\title{
Surgery and Caregiving: Loneliness of the Patients and Those Who Care for Them
}

\author{
Ami Rokach1,2,3*, Yona Miller3, Sharon Shick3, Rachel Abu3 ${ }^{3}$ Idit Matot ${ }^{4}$ \\ ${ }^{1}$ York University, Toronto, Canada \\ ${ }^{2}$ Walden University, Minneapolis, USA \\ ${ }^{3}$ Center for Academic Studies, Or Yehuda, Israel \\ ${ }^{4}$ Tel Aviv Medical Center, Tel Aviv, Israel \\ Email: arokach@yorku.ca
}

Received 20 January 2014; revised 20 February 2014; accepted 28 February 2014

Copyright (C) 2014 by authors and Scientific Research Publishing Inc.

This work is licensed under the Creative Commons Attribution International License (CC BY). http://creativecommons.org/licenses/by/4.0/

(c) (i) Open Access

\section{Abstract}

This research, conducted on patients and caregivers, examined the qualitative aspects of their loneliness. Patients were divided into those who were approached before they had surgery, and those post operatively. We collected information about their tumors, which were either benign or malignant. The patients' loneliness was compared to their caregivers who were either intimate partners or "others", i.e. family members and friends. The loneliness questionnaire, has already been extensively utilized in previous studies, and was used to explore the various aspects of loneliness of those groups. Significant differences in subscale scores were found in patients pre and post surgery, with those who have already had surgery scoring higher. Additionally, those who were cared for by a partner scored lower on the loneliness subscales than those attended to by "other". Interestingly, the only significant difference in the caregiver group was between men and women, in line with the socialization process of the genders, which makes women more open and vocal about their feelings and needs.

\section{Keywords}

Loneliness, Surgery, Patients, Caregivers, Hospitalization

\section{Introduction}

"Hospitalization and surgery are anxiety provoking events. Nearly all hospital patients experience some anxiety as a result of separation from home and family, loss of independence, and exposure to unfamiliar and unpleas-

\footnotetext{
${ }^{*}$ Corresponding author.
}

How to cite this paper: Rokach, A., Miller, Y., Shick, S., Abu, R. and Matot, I. (2014) Surgery and Caregiving: Loneliness of the Patients and Those Who Care for Them. Open Journal of Medical Psychology, 3, 222-234. 
ant medical procedures.” [[1]; p. 529].

Hospitalization happens. Surgery, while commonly feared, is a fact of life for many. The modern hospital environment is generally perceived to provide a safe and healing environment for people inflicted with a variety of illnesses, be it for short term visits and minor health problems or more serious conditions requiring long term treatment and care. Upon entering the health care system, patients nowadays receive the most contemporary care available, benefiting from modern technology in hands of professional and dedicated doctors and staff with most updated understanding of the human body and various treatments available [2] Rollins (2004). Although the modern hospital facility might be perceived as the "safety residence" that can provide the best quality care for people inflicted with health complications, the experience of illness and hospitalization, nonetheless, exerts a great deal of psychological distress. It is said to be one of the most distressful events people might actually experience in their life time [3].

Upon admission to the hospital, the reality for sick persons includes disruption in their daily routines and living environment, and an array of unwanted changes. For the duration of their stay they need to adapt to the hospital environment as their new home, resign themselves to the care of physicians and nurses, and get used to the unfamiliar surroundings and, often, unpleasant experiences associated with the course of treatment. And above all, the patient, as well as those individuals who care for him — family members and friends —often live in a state of constant worry, and are forced to instil their complete faith in the medical professionals at the hospital [4] [5]. The reality of this situation is that an individual and his or her family are not only subject to the debilitating aspects of the physical illness, but also to the added stressors inherent in the experience of being hospitalized [6] [7].

In addition to the technical aspects of care in the hospital facilities and the competency of the medical staff in caring for the patients, the attitude and behaviour of the doctors and the nurses towards the patients appears to be a key factor in perceived quality of care, and whether the patients can successfully cope with the stress of their hospitalization experience [1] [8]. This is essentially due to the fact that with the exception of the limited visiting time of their family and friends, hospitalized patients' social contact is limited to interaction with the medical staff. Albeit, this interaction is indeed that of an imbalanced nature; at one side are the patients, quite powerless, passive, weak and dependent due to their illness, and at the other side are the physicians, nurses, and supporting staff, who are in complete charge of almost every aspect of the patients care, with all the knowledge, authority and power that go with their positions [9] [10].

\subsection{Surgery}

Barker, Wright and Gonick [11] found that during physical illness which those who were scheduled for surgery went through, the patient's world undergoes a great "reduction" in scope and his psychological world become egocentric. Things that were previously important loose their importance, and only a small number of people and needs would affect and influence the person (see also Rokach \& Rokach, [12]). Surgery evokes fears which most surgical patients struggle with: anxiety due to anticipated pain and physical discomfort, worries concerning anesthesia and fears about having cancer or dying (see also Montgomery \& Bovbjerg [13]). The majority of those admitted to hospital for elective surgery experience anxiety preoperatively, and that may adversely influence surgical procedures as well as the patient's recovery (Batner et al. [14]).

Moerman [15] highlighted the pre-operative stress which is determined largely by feelings of anxiety. Expecting surgery as well as anaesthesia is fear inducing in patients. So much so, that those who experience preoperative anxiety, exhibit an increased number of cardiac arrhythmias during anesthesia, require more anesthetic drugs, suffer more post-operative pain, and their recovery is longer than the recovery of those who experienced less pre operative stress. It is reported that up to $60 \%$ of patients say that they are afraid of anesthesia [15]. Women report more anxiety than men and younger people are more anxious than older ones [16] [17]. Obviously, one's preoperative anxiety is related to the type of surgery one is to undergo [18]. Preoperative pain is one of the most important parameters in evaluating the effects of pre operative anxiety. Anxiety and fear are regarded as transmitters of pain. A variety of studies demonstrated that in the case of high preoperative anxiety, patients experience more post operative pain [19] [20]. Edell-Gustafson and Hetta [21] reviewed research that was done on patients who underwent Coronary Artery Bypass Grafting [CABG] and found that depression, and anxiety, and sleep disturbance were quite common following that type of surgery (see also Kagan \& Bar-Tal [22]).

Mitchell [23] observed that patients were found to be anxious about the anaesthetic, the surgery itself, possible pain and discomfort that may result, and waiting to be operated on.

The wait prior to surgery can be a very anxious time, since support from nurses may be limited, or absent, due 
to the unremitting surgical schedule. Apparently, the smooth operation of the surgical unit is the first priority of the nurse, and is more pressing for her than the patients' worries. The patient is often prior to surgery without having anyone to attend to his or her anxiety, questions, or concerns (Majasaari et al. [24]).

\subsection{Social Support \& Surgery}

"There is certainly ample evidence that social support can moderate the effects of psychological stress; in addition, a number of studies have shown relationships between social support and dimensions of autonomic, endocrine, and immune function, with family ties appearing to be a key source of support related to physiological functioning" (Kiecolt-Glaser et al., [25]; p. 1216).

Surgery is a threatening experience which includes multiple stressful concerns about one's physical condition, anticipation of painful procedures, worries about survival and recovery, and separation from family and friends. It was found that even surgeries that physicians consider as "minor" may provoke, in patients, strong psychological reactions [25]. Research demonstrated that the greater the stress and anxiety pre operatively, the slower and more complicated the post operative recovery [26]. And inversely, when psychosocial interventions were employed before surgery, they were shown to have positive physical and psychological effects post surgically (see reviews by Contrada, Leventhal \& Anderson, [26] [27].

Psychoneuroimmunology [PNI] research has provided evidence that stress and anxiety delay wound repair [28] [29]. The neuroendocrine and immune functioning following painful and tissue-damaging events, such as surgery is, have been well documented. Post operative elevations in plasma levels of epinephrine, cortisol, and beta-endorphine relflect sympathetic nervous system activation [30]. Immune suppression following surgery is evident due to suppression of Natural Killer Cell Activity [NKCA] [31]. "In general, high preoperative fear or stress is predictive of a variety of poorer outcomes, including greater pain, longer hospital stays, more postoperative complications, and poorer treatment compliance" (Kiecolt-Glaser et al., [31] p. 1214; see also Johnston [32]). As was earlier mentioned, support and caring can, significantly, assist the patient in addressing the pain and discomfort that, commonly, follow surgery [10].

\subsection{Loneliness}

Humans are fundamentally social creatures. Our quality of life depends on others. We thrive on social intercourse and consequently, when we become socially disconnected our psychological, physiological and even spiritual well-being may be negatively affected [33]. While we seek to satisfy our inherent need to belong, it is not just relationships that we are after, but we also need mutual concern and caring for those relationships to be satisfactory and growth promoting [34]. In support of the evolutionary perspective of belongingness, Olds and Schwartz [35] observed that socially connected people, indeed, live longer, have more robust immune systems, are better equipped to respond to stress, and are generally better off. Medical research has demonstrated that social connection is good and important to our health, or put even more poignantly "Human beings, both as a species and as individuals, survive only through attachment to one another... we are designed to become attached to one another" (Olds \& Schwartz, [35] p. 57).

Loneliness is a prevalent, common and disconcerting social phenomenon [36]. Recent estimates suggest that up to $32 \%$ of adults experience loneliness, and up to $7 \%$ report feeling intense loneliness [37]. In general, an over inclusive and somewhat simplistic view suggests that loneliness results when we perceive that our social relations are not up to par with our expectations (see also Rokach \& Sha'ked, [10]. Interestingly, it was found, lonely and non lonely people do not differ in the amount of time they spend alone, or in the daily activities they engage in [38]. Loneliness is a universal experience that does not respect the boundaries of age, gender, race, marital or socio economic status and it may be either persistent and continuous or short lived [38] [39].

Loneliness was found to be negatively correlated with happiness [40] and life satisfaction [41]. It has been linked to such maladies as depression, hostility, alcoholism, poor self-concept, and psychosomatic illnesses [39]. Recent studies suggest that a large proportion of the population feel lonely frequently [10] [42].

\subsection{Caregivers}

Rosalynn Carter suggested that "there are four types of people: those who are caregivers; those who have been caregivers; those who will be caregivers; and those who will need caregivers". (in Dwyer, [43], p. 20)

Novotney [44] reported that in any given year, caregivers, or unpaid caretakers, number about 67 million in 
the U.S. These caregivers are tending to children, spouses, ailing and old parents, and other loved ones who may have disabling or incapacitating illnesses. Caregivers do their tending, usually, in addition to work, school, or other responsibilities. It is reported that they spend as many as 20 weekly hours on these duties which may include making sure that their loved ones take their medicines appropriately and on time, helping them bath and clothing them, and even helping to pay their medical bills. For patients with conditions such as Alzheimer's disease, the weekly hours may approach 60 !

Caring for the ill person creates considerable strain for caregivers and may affect their working schedule, family life, and social relationships [10]. It is, consequently, of no surprise that caregiving is frequently associated with significant physical and psychological vulnerability. Their distress, reported the authors, is evident in the form of depression, anxiety, anger, health problems, and loneliness [45]. Alarmingly, 14\% of caregivers admitted entertaining suicidal thoughts [46]. Both seeing the suffering of a loved one without being able to ease the pain or prevent death, as well as facing one's own mortality and small stature in the "big scheme of things," may result in loneliness and alienation from the rest of the healthy and bustling society. Caregiver burden is positively related with his/her depression and negatively with patient functions [47]. Furthermore, a positive correlation between caregiver anxiety and their perception of social support, was also found by these researchers. These findings are reported to be consistent with other studies on caregivers [48] [49].

It is clear that perceived social support is an important predictor of carers' distress [50], their marital relationship satisfaction [51] and patient's and caregiver's quality of life [52]. However, maintaining a social support network may not be easily achieved, as friends and acquaintances often stop visiting or do visit but behave awkwardly due to increased severity of the patient's symptoms [10] [53].

\subsection{The Present Study}

Since loneliness is such a pervasive experience, and hospitalization such an anxiety arousing one, since all of us have experienced loneliness at one time or another in our lives, and since many may have to undergo hospitalization and surgery, it stands to reason that hospitalized people, and especially those scheduled for surgery, will experience loneliness. While they may be surrounded and supported by family and friends, they are the ones who have to undergo whatever procedures that await them. We, consequently, explored the qualitative aspects of loneliness of those who were hospitalized prior to, and post surgery, and that of their caregivers.

\section{Method}

\subsection{Participants}

Four hundred and twenty one participants volunteered to take part in our study. A total of 210 men and 211 women comprised the sample. Participants were divided into three groups: 1) ENT Patients [representing hospitalized patients] prior to surgery 2) ENT patients post surgery, and 3) caregivers. The average age of all participants was 44 years with ages ranging between 16 - 88. The mean level of education (i.e. last grade completed) was 13.5 years with a range of 1 - 23. Thirty five percent of the participants were not married or not lived with partner, 65\% were married or lived with partner. No significant differences were found between gender, age, education, and marital status between the three groups. Significant age differences were found between benign and cancer patients in each group. Cancer patients were significantly older than benign patients. Age was covaried in further analyses.

\subsection{Procedure}

The ill patients and their caregivers were recruited in an Ear, Nose and Throat [ENT] department in a major hospital in central Israel. Each patient and each caregiver were approached by the attending nurses on the floor, and asked to participate in this study anonymously. Participants were asked to reflect on their loneliness experience and to endorse those items which described it. Those patients unable to read or write were assisted by a researcher. Questions that the patients, or their families, may have had were answered while the participants were answering the questionnaire. They took approximately 15 minutes to answer the questionnaire. Caregivers provided demographic data which included their degree of closeness to the patient. The study was approved by the hospital's Institutional Review Board. 


\subsection{The Loneliness Questionnaire}

All items for the questionnaire were written by the senior author and based on Rokach's previous research on loneliness [42] [54]. The model, on which the questionnaire was based, contains five factors. The most salient factor to emerge was Emotional distress (which accounted for 19\% of the variance). This included items that captured the intense pain, inner turmoil, hopelessness, and feelings of emptiness associated with loneliness [i.e. "I experienced being overwhelmed with feelings of dread"; "I experienced feelings of intense hurt"]. The second factor, Social inadequacy and alienation (7\% of the variance) addressed the perception and concomitant self-generated social detachment that were reported as part of loneliness experience ["I felt that people wanted nothing to do with me"; "I felt I was boring and uninteresting"]. The third factor, Growth and discovery (4\% of the variance) captured the positive, growth-enhancing, and enriching aspects of loneliness and the increased feelings of inner strength and self-reliance that follow ["I discovered a personal strength I was previously unaware of"; "I have greater confidence in myself"]. Interpersonal isolation (3\% the variance) was the fourth factor. It depicted feelings of alienation, abandonment, and rejection, which were reported as related to a general lack of close relationships and/or absence of a primary romantic relationship ["I felt the absence of a meaningful romantic relationship"; I felt I had no one I could lean on in a time of need"]. The fifth factor, Self-alienation (3\% of the variance) described a detachment from one's self that is characterized by numbness, immobilization and denial ["I felt as if my mind and body were in different places"; I felt that I was observing myself as if I was another person"]. In all, these factors accounted for $36 \%$ of the variance. Each factor was a subscale in the questionnaire and participants' scores are the sum of items they endorsed in each subscale. The questionnaire had 30 items that describe the experience of loneliness. It was comprised of five scales each had six items. The general instructions request that participants reflect on their experience of loneliness and endorse the items that describe them. Kuder-Richardson internal consistency reliabilities were calculated and yielded the following alpha values: Emotional distress $=0.77$, Social Inadequacy and Alienation $=0.71$, Growth and discovery $=0.83$, Interpersonal isolation $=0.72$, Self-alienation $=0.69$. K-R alpha for the 30-item questionnaire was 0.86 . The questionnaire was translated into Hebrew by bilingual Canadian students, and was then verified and edited by an Israeli academician.

\section{Results}

Results indicated that the quality of the experience of loneliness of patients was influenced by whether they were facing surgery, or were already "done with it". Similarly, the closeness of their caregiver, whether a partner or a somewhat more distanced family member/friend, affected their loneliness. Interestingly, similar differences were not observed in the caregivers. What made a difference in that group is their gender, rather than their closeness to the patient, or whether he was before or after surgery. Table 1 reviews and compares the demographic data of the various groups.

Table 2 compared the mean subscale scores on each of the five factors of loneliness experience between patients before and after surgery, between benign and cancer patients between patients with different main supporters using a MANCOVA (age was covaried). Significant differences were found between patients before and after surgery $\left(\mathrm{F}_{(5,311)}=4.19, \mathrm{p}<0.01\right)$. Consequently, univariate ANCOVAs for each of the subscales were conducted. Patients after surgery had higher subscale scores on all five factors. Emotional distress $\left(\mathrm{F}_{(1,315)}=\right.$ 11.31, $\mathrm{p}<0.01)$, Social inadequacy \& alienation $\left(\mathrm{F}_{(1,315)}=12.37, \mathrm{p}<0.01\right)$, Growth \& discovery $\left(\mathrm{F}_{(1,315)}=5.56\right.$, $\mathrm{p}<0.05)$, Interpersonal isolation $\left(\mathrm{F}_{(1,315)}=4.18, \mathrm{p}<0.05\right)$, Self-alienation $\left(\mathrm{F}_{(1,315)}=12.25, \mathrm{p}<0.01\right)$. No significant differences were found in the average scores of the subscales between benign and cancer patients before surgery $\left(\mathrm{F}_{(5,136)}=0.55\right.$, n.s. $)$ and after surgery $\left(\mathrm{F}_{(5,158)}=1.47\right.$, n.s.). Significant differences were indeed found in the mean subscale scores between patients whose supporter is his/her partner and those whose supporter is other person $\left(\mathrm{F}_{(5,298)}=3.90, \mathrm{p}<0.01\right)$. Univariate ANCOVAs for each of the subscales were conducted. Patients with other supporter had higher subscale scores on four factors. Emotional distress $\left(\mathrm{F}_{(1,302)}=4.64, \mathrm{p}<0.05\right)$, Social inadequacy \& alienation $\left(\mathrm{F}_{(1,302)}=5.53, \mathrm{p}<0.05\right)$, Growth \& discovery $\left(\mathrm{F}_{(1,302)}=5.35, \mathrm{p}<0.05\right)$, Interpersonal isolation $\quad\left(\mathrm{F}_{(1,302)}=12.10, \mathrm{p}<0.01\right)$. Significant differences were found between benign patients before and after surgery $\left(\mathrm{F}_{(5,221)}=2.61, \mathrm{p}<0.05\right)$. Univariate ANCOVAs for each of the subscales were conducted. Benign patients after surgery had higher subscale scores on four factors. Emotional distress $\left(\mathrm{F}_{(1,225)}=7.60, \mathrm{p}<0.01\right)$, Social inadequacy $\left(\mathrm{F}_{(1,225)}=8.03, \mathrm{p}<0.01\right)$, Interpersonal isolation $\left(\mathrm{F}_{(1,225)}=4.02, \mathrm{p}<0.05\right)$, Self-alienation $\left(\mathrm{F}_{(1,225)}=8.75, \mathrm{p}<0.01\right)$. No significant difference were found between cancer patients before and after surgery 
Table 1. Demographics.

\begin{tabular}{|c|c|c|c|c|c|c|c|c|c|c|c|}
\hline \multirow[b]{2}{*}{ population } & \multirow[b]{2}{*}{$\mathbf{N}^{1}$} & \multicolumn{2}{|c|}{ Gender } & \multicolumn{2}{|c|}{ Marital status } & \multicolumn{3}{|c|}{ Education } & \multicolumn{3}{|c|}{ Age } \\
\hline & & Male & Female & $\begin{array}{l}\text { married/living } \\
\text { with partner }\end{array}$ & $\begin{array}{c}\text { Not } \\
\text { married }\end{array}$ & M & & SD & M & & SD \\
\hline $\begin{array}{l}\text { Patient } \\
\text { before }\end{array}$ & 157 & $\begin{array}{c}80 \\
51 \%\end{array}$ & $\begin{array}{c}77 \\
49 \%\end{array}$ & $\begin{array}{c}91 \\
59.9 \%\end{array}$ & $\begin{array}{c}61 \\
40.1 \%\end{array}$ & 13.20 & $(1-21)^{2}$ & 2.70 & 43.80 & $(16-89)$ & 16.50 \\
\hline Benign & 108 & $\begin{array}{c}52 \\
48.1 \%\end{array}$ & $\begin{array}{c}56 \\
51.9 \%\end{array}$ & $\begin{array}{c}55 \\
52.4 \%\end{array}$ & $\begin{array}{c}50 \\
47.6 \%\end{array}$ & 13.10 & $(1-19)$ & 2.52 & 41.31 & $(16-76)$ & 15.68 \\
\hline Cancer & 38 & $\begin{array}{c}22 \\
57.9 \%\end{array}$ & $\begin{array}{c}16 \\
42.1 \%\end{array}$ & $\begin{array}{c}28 \\
73.7 \%\end{array}$ & $\begin{array}{c}10 \\
26.3 \%\end{array}$ & 13.76 & $(4-21)$ & 3.26 & $\begin{array}{c}49.80 \\
\mathrm{t}_{(141)}=2.75^{* *}\end{array}$ & $(20-89)$ & 13.76 \\
\hline $\begin{array}{c}\text { Patient } \\
\text { after }\end{array}$ & 172 & $\begin{array}{c}94 \\
51.7 \%\end{array}$ & $\begin{array}{c}78 \\
45.3 \%\end{array}$ & $\begin{array}{c}108 \\
64.3 \%\end{array}$ & $\begin{array}{c}60 \\
35.7 \%\end{array}$ & 13.50 & $(1-23)$ & 2.70 & 44.10 & $(15-82)$ & 17.40 \\
\hline Benign & 126 & $\begin{array}{c}70 \\
55.6 \%\end{array}$ & $\begin{array}{c}56 \\
44.4 \%\end{array}$ & $\begin{array}{c}78 \\
62.4 \%\end{array}$ & $\begin{array}{c}47 \\
37.6 \%\end{array}$ & 13.43 & $(1-20)$ & 2.59 & 41.80 & $(15-82)$ & 17.28 \\
\hline Cancer & 43 & $\begin{array}{c}22 \\
51.2 \%\end{array}$ & $\begin{array}{c}21 \\
48.8 \%\end{array}$ & $\begin{array}{c}30 \\
69.8 \%\end{array}$ & $\begin{array}{c}13 \\
30.2 \%\end{array}$ & 13.70 & $(8-23)$ & 3.03 & $\begin{array}{c}50.48 \\
t_{(163)}=2.86^{* *}\end{array}$ & $(16-79)$ & 15.98 \\
\hline Caregivers & 92 & $\begin{array}{c}36 \\
39.1 \%\end{array}$ & $\begin{array}{c}56 \\
60.9 \%\end{array}$ & $\begin{array}{c}55 \\
71.4 \%\end{array}$ & $\begin{array}{c}22 \\
28.6 \%\end{array}$ & 13.87 & $(8-22)$ & 2.27 & 44.20 & $(19-83)$ & 15.40 \\
\hline Benign & 60 & $\begin{array}{c}36 \\
39.1 \%\end{array}$ & $\begin{array}{c}56 \\
60.9 \%\end{array}$ & $\begin{array}{c}69 \\
73.4 \%\end{array}$ & $\begin{array}{c}25 \\
26.6 \%\end{array}$ & 14.05 & $(8-22)$ & 2.37 & 42.75 & $(19-83)$ & 15.4 \\
\hline Cancer & 20 & $\begin{array}{c}7 \\
35.0 \%\end{array}$ & $\begin{array}{c}13 \\
65.0 \%\end{array}$ & $\begin{array}{c}12 \\
60.0 \%\end{array}$ & $\begin{array}{c}8 \\
40.0 \%\end{array}$ & 13.35 & $(10-17)$ & 1.93 & 47.78 & $(21-75)$ & 13.98 \\
\hline Total & 421 & $\begin{array}{l}210 \\
49.9 \%\end{array}$ & $\begin{array}{c}211 \\
50.1 \%\end{array}$ & $\begin{array}{c}270 \\
64.7 \%\end{array}$ & $\begin{array}{c}147 \\
35.3 \%\end{array}$ & 13.50 & $(1-23)$ & 2.60 & 44.00 & $(16-88)$ & 16.60 \\
\hline
\end{tabular}

${ }^{1}$ Frequencies might not add up due to missing data. ${ }^{2}$ Range in parentheses. No significant differences found in gender, marital status, education, age between the groups. Significant differences found in age between benign and cancer patients within the group before surgery and after surgery.

Table 2. Comparing mean scores of coping with loneliness (patients).

\begin{tabular}{|c|c|c|c|c|c|c|c|c|c|c|c|c|c|}
\hline \multirow[t]{2}{*}{ Population } & \multirow[t]{2}{*}{$\mathrm{N}^{1}$} & \multicolumn{2}{|c|}{$\begin{array}{c}\text { Reflection \& } \\
\text { acceptance }\end{array}$} & \multicolumn{2}{|c|}{$\begin{array}{l}\text { Self-development } \\
\text { \& understanding }\end{array}$} & \multicolumn{2}{|c|}{$\begin{array}{l}\text { Social support } \\
\text { network }\end{array}$} & \multicolumn{2}{|c|}{$\begin{array}{c}\text { Distancing \& } \\
\text { denial }\end{array}$} & \multicolumn{2}{|c|}{ Religion \& faith } & \multicolumn{2}{|c|}{$\begin{array}{l}\text { Increased } \\
\text { activity }\end{array}$} \\
\hline & & M & SD & M & SD & M & $\mathrm{SD}$ & M & SD & M & SD & M & $\mathrm{SD}$ \\
\hline Before (total) & 151 & 1.46 & 1.66 & 0.29 & 0.58 & 1.18 & 1.47 & 0.17 & 0.50 & 0.35 & 0.78 & 1.04 & 1.29 \\
\hline Benign & 105 & 1.36 & 1.59 & 0.29 & 1.36 & 1.31 & 1.51 & 0.19 & 0.53 & 0.33 & 0.72 & 1.06 & 1.29 \\
\hline Cancer & 38 & 1.74 & 1.83 & 0.92 & 0.56 & 0.82 & 1.31 & 0.13 & 0.41 & 0.42 & 0.94 & 1.00 & 1.27 \\
\hline \multicolumn{14}{|l|}{$\begin{array}{c}\text { MANCOVA }^{2} \\
\mathrm{~F}_{(6,135)}=.90\end{array}$} \\
\hline After (total) & 165 & 1.84 & 1.78 & 0.54 & 0.96 & 1.23 & 1.34 & 0.22 & 0.52 & 0.52 & 0.94 & 1.36 & 1.34 \\
\hline Benign & 123 & 1.82 & 1.74 & 0.54 & 0.96 & 1.31 & 1.36 & 0.20 & 0.49 & 0.46 & 0.94 & 1.33 & 1.21 \\
\hline Cancer & 42 & 1.90 & 1.91 & 0.55 & 0.97 & 1.00 & 1.28 & 0.31 & 0.60 & 0.69 & 0.95 & 1.48 & 1.70 \\
\hline \multicolumn{14}{|l|}{$\begin{array}{l}\text { MANCOVA }^{2} \\
\mathrm{~F}_{(6,157)}=1.20\end{array}$} \\
\hline Total & 318 & 1.65 & 1.74 & 0.42 & 0.82 & 1.19 & 1.41 & 0.20 & 0.52 & 0.45 & 0.88 & 1.22 & 1.35 \\
\hline $\begin{array}{c}\text { Total MANCOVA } \\
F_{(6,310)}=2.50^{*} \\
\eta^{2}=0.04\end{array}$ & & $\begin{array}{c}\mathrm{F}_{(1,315)}= \\
4.97^{*}\end{array}$ & $\eta^{2}=.02$ & $\begin{array}{l}\mathrm{F}_{(1,315)}= \\
8.58^{* *}\end{array}$ & $\eta^{2}=.03$ & & & & & & & $\begin{array}{c}\mathrm{F}_{(1,315)} \\
5.94^{*}\end{array}$ & $\eta^{2}=.02$ \\
\hline $\begin{array}{c}\text { Main support- } \\
\text { partner }\end{array}$ & 212 & 1.58 & 1.74 & 0.42 & 0.88 & 1.06 & 1.31 & 0.16 & 0.44 & 0.48 & 0.92 & 1.11 & 1.29 \\
\hline $\begin{array}{c}\text { Main support- } \\
\text { other }\end{array}$ & 102 & 1.80 & 1.77 & 0.42 & 0.66 & 1.46 & 1.58 & 0.31 & 0.64 & 0.39 & 0.81 & 1.43 & 1.44 \\
\hline \multicolumn{13}{|l|}{ MANCOVA $^{2}$} & $F_{(6,306)}=2.06$ \\
\hline \multicolumn{14}{|l|}{$\begin{array}{l}\text { Benign before Vs. } \\
\text { Benign after } F_{(6,234)} \\
\quad=1.55\end{array}$} \\
\hline $\begin{array}{c}\text { Cancer before Vs. } \\
\text { Cancer after } \\
\mathrm{F}_{(6,74)}=0.83\end{array}$ & & & & & & & & & & & & & \\
\hline
\end{tabular}


$\left(\mathrm{F}_{(5,73)}=1.76\right.$, n.s. $)$.

Table 3 compared the mean subscale scores on each of the five factors of loneliness experience among caregivers of benign and cancer patients, among caregivers who are the patient's partner or other patient relative, among male or female care givers. No significant differences were found between caregivers of benign patients and caregivers of cancer patient. No significant differences were found between caregivers who are the patient's partner or other relative. Significant differences were found between male and female caregivers in two out of five factors. Female had higher subscale scores on Emotional distress $\left(F_{(1,68)}=9.02, p<0.01\right)$ and in Social inadequacy $\left(\mathrm{F}_{(1,68)}=4.21, \mathrm{p}<0.05\right)$.

\section{Discussion}

The present study demonstrated that, as we expected, loneliness was indeed affected by surgery. It appears that surgery and hospitalization are so stressful and significantly contribute to loneliness, that the kind of tumour that had to be operated on — cancerous or benign — did not significantly contribute to one's loneliness. We also found that caregivers, again as expected, made a difference in the loneliness experienced by those awaiting surgery. Patients who had their intimate partner attend to them, either before or following surgery, had lower subscale scores than those who were cared for by others-friends, or family members other than one's partner. When we examined the loneliness of those assisting and caring for patients before or after surgery, and the patients' group (those with malignant or benign tumors), we found no difference in the manner in which they experienced loneliness. The common gender difference was found, with women reporting higher levels of Emotional distress and Social inadequacy and alienation.

Illness itself is a major stressor in one's life. Various symptoms and effects of the illness put the body into a state of continuous stress, including pain, fatigue, and in more severe cases, immobility and even loss of bodily functions and control [55]. In general, it is not only the physical suffering and distress that puts the body into a state of such continuous stress, but also factors that negatively affect the patient's psychological state [56]. Factors such as perceived threat to ones' life and the uncontrollable and unpredictable nature of one's condition, often put hospitalized individuals in a state of apprehension and hopelessness, which can have a considerable effect on their thoughts, emotions, and subsequent behaviours [10] [57]-[59]. Simple things like having to eat the hospital food, or having to sleep on a different bed, may bring about emotional discomfort, simply because patients can no longer "feel at home", and have minimal personal control over their choices and surrounding environment for as long as they need to stay in hospital [7] [60]. And while, awaiting surgery may be more anxiety arousing than the time after surgery, it may be that only once that anxiety is lowered after surgery that patients

Table 3. Comparing mean scores of coping with loneliness (Caregivers).

\begin{tabular}{|c|c|c|c|c|c|c|c|c|c|c|c|c|c|}
\hline \multirow[t]{2}{*}{ Population } & \multirow[t]{2}{*}{$\mathrm{N}^{1}$} & \multicolumn{2}{|c|}{$\begin{array}{c}\text { Reflection \& } \\
\text { acceptance }\end{array}$} & \multicolumn{2}{|c|}{$\begin{array}{l}\text { Self-development } \\
\& \text { understanding }\end{array}$} & \multicolumn{2}{|c|}{$\begin{array}{c}\text { Social support } \\
\text { network }\end{array}$} & \multicolumn{2}{|c|}{$\begin{array}{c}\text { Distancing \& } \\
\text { denial }\end{array}$} & \multicolumn{2}{|c|}{ Religion \& faith } & \multicolumn{2}{|c|}{$\begin{array}{c}\text { Increased } \\
\text { activity }\end{array}$} \\
\hline & & M & SD & M & SD & M & SD & M & SD & M & SD & M & SD \\
\hline Total & 71 & 1.82 & 1.76 & 0.66 & 1.12 & 1.37 & 1.55 & 0.14 & 0.48 & 0.59 & 0.96 & 1.25 & 1.47 \\
\hline Benign & 53 & 1.96 & 1.39 & 0.62 & 1.14 & 1.53 & 1.67 & 0.13 & 0.52 & 0.57 & 0.93 & 1.38 & 1.52 \\
\hline Cancer & 18 & 1.39 & 1.33 & 0.78 & 1.06 & 0.89 & 1.02 & 0.17 & 0.38 & 0.67 & 1.08 & 0.89 & 1.28 \\
\hline \multicolumn{14}{|l|}{$\begin{array}{c}\text { MANCOVA }^{2} \\
\mathbf{F}_{(6,63)}=0.71\end{array}$} \\
\hline Partner & 51 & 1.57 & 1.78 & 0.57 & 0.98 & 1.16 & 1.41 & 0.10 & 0.45 & 0.61 & 1.00 & 1.18 & 1.46 \\
\hline Other & 24 & 1.96 & 1.51 & 0.75 & 1.32 & 1.67 & 1.88 & 0.21 & 0.50 & 0.50 & 0.88 & 1.29 & 1.45 \\
\hline \multicolumn{14}{|l|}{$\begin{array}{c}\text { MANCOVA }^{2} \\
F_{(6,67)}=0.40\end{array}$} \\
\hline Male & 34 & 1.26 & 1.58 & 0.17 & 0.58 & 1.35 & 1.47 & 0.06 & 0.34 & 0.41 & 0.89 & 0.94 & 1.25 \\
\hline Female & 51 & 2.12 & 1.78 & 0.82 & 1.21 & 1.39 & 1.65 & 0.15 & 0.50 & 0.63 & 0.95 & 1.41 & 1.50 \\
\hline $\begin{array}{l}\text { MANCOVA } \\
\mathbf{F}_{(6,77)}=2.70^{*}\end{array}$ & & $\mathrm{~F}_{(1,82)}=$ & $\eta^{2}=0.05$ & $\begin{array}{l}\mathrm{F}_{(1,82)}= \\
8.31^{* *}\end{array}$ & $\eta^{2}=0.09$ & & & & & & & & \\
\hline
\end{tabular}


can experience, more sharply, the loneliness that hospitalization and surgery are known to foster.

\subsection{Patients}

Surgery evokes fears which most surgical patients struggle with: anxiety due to anticipated pain and physical discomfort, worries concerning anesthesia and fears about having cancer or dying (see also Montgomery et al. [13]). Kiecolt-Glaser et al. [31] observed that "surgery is a threatening experience with multiple stressful components - concerns about one’s physical conditions, admission to a hospital, anticipation of painful procedures, worries about survival and recovery, and separation from family. Accordingly, it is not surprising that operations that physicians consider "minor" can provoke strong emotional reactions in patients" (p. 1209). What may have, prior to surgery, been highly important is viewed now differently, and only a small number of people or unfulfilled needs would affect and influence the person. Mitchell [23] observed that patient anxiety is an important issue prior to day surgery and general anaesthesia [61] [62]. Elkins, Rajab, Marcus \& Staniunas [63] echoed this observation and highlight the stress and anxiety that patients experience before surgery. It, consequently, stands to reason that regardless of whether their surgery involved malignant or benign tumors, the overriding stressor was the actual surgery, and as such loneliness post operatively was experienced more acutely than for those expecting from surgery. It is suggested that the stress and anxiety prior to surgery are so overwhelming, that loneliness is a lesser concern for patients. However, following surgery with its consequent pain, discomfort and dependence on others for help, patients will be more tuned to their loneliness and feelings of isolation that hospitalization fosters [3] [15].

When comparing the loneliness subscale scores of patients with benign and malignant tumors before surgery, and then those two groups post operatively no significant difference in loneliness subscale scores was reported. The literature suggested that cancer patients, due to constraints and restrictions of the illness often experience difficulties in interpersonal relationships [2] [60] [64] [65].

As the ability to cope with the disease decreases, so do the quality of their social interactions [66]-[68]. Interestingly, when we examined the loneliness of patients pre and post surgery, there was no significant difference in the subscale scores of those with malignant tumours pre and post operatively. However, in patients with benign tumours when compared pre and post surgery, it was found that they had significantly higher scores on four of the five loneliness subscales following surgery. As was previously mentioned, it is seen as a testament to the overwhelming threat that surgery may signify for one's existence. A threat that may minimize, at that point, all other concerns (see also Polimeni and Moore, [69]). However, post surgery, once the pain and discomfort may be attended to medically, the person is open to examine his situation and feelings and experience [among others] also loneliness. Requiring constant care, together with the experience of, at times, severe pain and discomfort render patients immobilized, confounded to bed, and often connected to multiple intravenous devices. These patients are, then, exposed to a monotonous and uncomfortable environment of sensory overload over an extended period of time [70] [71].

We compared the subscale scores of patients, according to the level of closeness of their caregiver: intimate partner vs. a family member or friend. As could be expected, and so intuitively clear, patients with a more distanced and less connected caregiver resulted in higher subscale scores on all loneliness scales except Growth and discovery. It seems that closeness to one's caregiver has no significant effect on the personal growth that one may experience when being lonely. While intimate partners are often close to and supportive [if not emotionally, at least physically and medically] of the patient. Singer [72] asserted that because it is part of human nature to avoid pain, surgical cancer and even non cancer patients and their families often experience difficulty relating to each other and working with the problem at hand in a constructive way (see also Brown et al., 2006). Again, an indication that a close intimate partner's support may be more helpful in handling loneliness than a friend or family member's caregiving [73].

\subsection{Caregivers}

And what about the caregivers themselves? How is their level of loneliness affected by the presence or absence of cancer in the patients they cared for? It is predicted that within the next 50 years, the total number of cancer cases is expected to double, thereby likely increasing the prevalence of informal caregiving. Informal caregiving is often a mentally, socially, and emotionally overwhelming experience that can engender a profound sense of loneliness [74]. Even if caregivers are able to find time to engage in social activities, they may be less able to 
derive concomitant psychological benefits if they feel guilty and anxious seeing that they are "giving up temporarily" their caregiving responsibilities. Caregiving being so very demanding can disrupt one's working schedule, family life, and social relationships, thus rendering it difficult to maintain desired levels of social involvement [74] [75]. Being the sole primary caregiver (as is often the case), may result in caregivers feeling unsupported by family and friends who go on with their lives, thus compounding their sense of loneliness (see also Montgomery et al., [13]). Finally, caregivers who must helplessly witness the suffering of a loved one, while simultaneously facing their own mortality, may result in loneliness and alienation from the rest of the healthy and bustling society. Seeing the suffering of a loved one without being able to ease the pain or prevent death, as well as, via that facing one's own mortality, may result in loneliness and alienation from the rest of the healthy and bustling society [46]. Caring for the seriously ill person creates considerable strain for caregivers and may affect their working schedule, family life, and social relationships. It is, therefore, obvious why caregiving is frequently associated with significant psychological and physical vulnerability. That may include depression, anxiety, anger, health problems, loneliness [45], and suicidality. Consequently, it was found in the present study that the patient's diagnosis or even stress and anxiety related to surgery do not affect the loneliness of caregivers. What does seems to make a difference is their gender. Women had higher subscale scores than men on Emotional distress and Social inadequacy and alienation.

Rokach and Brock [42] [76] found consistent differences in the reported experiences of loneliness between North American men and women. The present result is in line with previous research that highlighted women's socialization in the Western world. Women are adept at self-reflection, expressing their emotions, and being tuned into what they feel and how they act, more than men do (see for example [77]. Riches [78] described the loneliness that is commonly experienced by the ill and by their caregivers. During this period of illness, treatments and questions about the patient's future, we would intuitively expect that caregivers will engage in reflection about their situation and it's ramification on their own future. It may help explain the higher scores that women caregivers received on the Acceptance \& reflection subscale, since men are culturally not trained, or encouraged, to reflect and attend to their emotions [10]. The demanding nature of caregiving can disrupt one's working schedule, family life, and social relationships, thus rendering it difficult to maintain desired levels of social involvement [12]. Even if caregivers are able to find time to engage in social activities, they may be less able to derive concomitant psychological benefits if confronted with guilt and anxiety around their reprieve from caregiving [74].

\subsection{Limitations of the Study}

The present study has several limitations, and it is hoped that future research may address them. Firstly, while we researched and collected data from patients who were scheduled or had already undergone surgery, we did not inquire about their experience with prior surgeries, which may influence significantly their anxiety and view of their present situation. We also did not differentiate the type of surgery the patients have undergone, aside from noting whether they were treated for malignant or benign conditions, and only in the ENT department. Future research will, hopefully collect data from patients of other departments, and cover all kinds of surgical interventions. Croog et al. [79] maintained that "such characteristics as pre-operative fear, anxiety, depression, low self-esteem, an external locus of control... are associated with a negative past surgical experience” (p. 40). None of these variables were examined, and they could, indeed, affect pre and post surgical experiences.

Montgomery et al. [13] indicated that "Pre surgery distress contributes to variability in patients' post surgery outcome [e.g. pain]” (p. 382). We have not examined the level of pre surgery distress, or the patients' level of pain and discomfort post surgery. These variables, as well, could have affected the loneliness that the patients and their caregivers experienced.

Korporaal, Broese van Groenou, \& van Tilburg [80] noted that one’s own and one’s partner's disabling health problems can negatively influence someone's well-being. Additionally, they observed, that caring for a disabled spouse is a risk factor for one's own health. Our study did not explore either the severity of the disability that the illness may have caused, nor the effect it had on married/common-law couples.

To conclude, patients and their caregivers experience loneliness when one is hospitalized, and has to undergo surgery. Being such a stress inducing and threatening experience, surgery once it is over, allows the patient to more acutely experience loneliness, and not just the fear, stress, and even existential anxiety that may have been previously experienced. Loneliness, as research repeatedly demonstrated is part and parcel of the process of be- 
ing hospitalized and operated on. It is more acutely experienced after surgery, when the anticipatory anxiety gives way to one's discomfort and dependence on others, and thus to reflection on how one feels and his experience in hospital.

\section{References}

[1] Hartsfield, J. and Clopton, J.R. (1985) Reducing Presurgical Anxiety: A Possible Visitor Effect. Social Science and Medicine, 20, 529-533. http://dx.doi.org/10.1016/0277-9536(85)90369-7

[2] Rollins, J.A. (2004) Evidence-Based Hospital Design Improves Health Care Outcomes for Patients, Families and Staff. Pediatric Nursing, 30, 338-339.

[3] Hughes, B.M. (2001) Psychology, Hospitalization and Some Thoughts on Medical Training. European Journal of Psychotherapy \& Counselling, 4, 7-26. http://dx.doi.org/10.1080/13642530110040109

[4] Hallström, I. and Elander, G. (2007) Families’ Needs When a Child Is Long-Term Ill: A Literature Review with Reference to Nursing Research. International Journal of Nursing Practice, 13, 193-200. http://dx.doi.org/10.1111/j.1440-172X.2007.00625.x

[5] Paul, F. and Rattray, J. (2008) Short- and Long-Term Impact of Critical Illness Relatives: Literature Review. Journal of Advanced Nursing, 62, 276-292. http://dx.doi.org/10.1111/j.1440-172X.2007.00625.X

[6] Rokach, A. and Matalon, R. (2007) “Tails”-A Fairy Tale on Furry Tails: A 15-Year Theatre Experience for Hospitalized Children Created by Health Professionals. Paediatric Child Health, 12, 301-304.

[7] Williams, A. M. and Irurita, V. F. (2005) Enhancing the Therapeutic Potential of Hospital Environment by Increasing the Personal Control and Emotional Comfort of Hospitalized Patients. Applied Nursing Research, 18, 22-28. http://dx.doi.org/10.1016/j.apnr.2004.11.001

[8] Attree, M. (2001) Patients' and Relatives’ Experiences and Perspectives of “Good” and “Not so Good” Quality Care. Journal of Advanced Nursing, 33, 456-466. http://dx.doi.org/10.1046/j.1365-2648.2001.01689.x

[9] Thomas, L.H. and Bond, S. (1996) Measuring Patients' Satisfaction with Nursing: 1990-1994. Journal of Advanced Nursing, 23, 747-756. http://dx.doi.org/10.1111/j.1365-2648.1996.tb00047.x

[10] Rokach, A. and Sha’ked, A. (2013) Together and Lonely: Loneliness in Intimate Relationships—Causes and Coping. Nova Pub, NY.

[11] Barker, R., Wright, B. and Gonick, M. (1946) Adjustment to Physical Handicap and Illness: A Survey of the Social Psychology of Physique and Disability. Social Science Research Council, New York. http://dx.doi.org/10.1037/11780-000

[12] Rokach, B. and Rokach, A. (2013) Medicine, Radiology, Hospitalization, and Loneliness. In: Rokach, A., Ed., Loneliness Updated: Recent Research on Loneliness and How It Affects our Life (pp. 270-283). Routledge, Abingdon.

[13] Montgomery, G.H. and Bovbjerg, D.H. (2004) Presugery Distress and Specific Response Expectancies Predict Postsurgery Outcomes in Surgery Patients Confronting Breast Cancer. Health Psychology, 23, 381-387. http://dx.doi.org/10.1037/0278-6133.23.4.381

[14] Batner, N.H., Nielson, W.R., Munk, S., Kwiatkowska, C.K. and Gelb, A.W. (1990) Preoperative Anxiety: Detection and Contributing Factors. Canadian Journal of Anaesthesiology, 27, 444-447. http://dx.doi.org/10.1007/BF03005624

[15] Moerman, N. (1996) Psychological Aspects of Anesthesia. CIP-DATA Koninklijke Bibliotheek, Haag.

[16] McCleane, G.J. and Cooper, R. (1990) The Nature of Preoperative Anxiety. Anaesthesia, 45, 153-155. http://dx.doi.org/10.1111/j.1365-2044.1990.tb14285.x

[17] Shevde, K. and Panagopoulos, G. (1990) A Survey of 800 Patients’ Knowledge, Attitudes, and Concerns Regarding Anesthesia. Anesthesia \& Analgesia, 73, 190-198.

[18] Mackenzie, J.W. (1989) Daycase Anaesthesia and Anxiety. A Study of Anxiety Profiles amongst Patients Attending a Day Bed Unit. Anaesthesia, 44, 679-682. http://dx.doi.org/10.1111/j.1365-2044.1989.tb11349.x

[19] Craig, K.D. (1989) Emotional Aspects of Pain. In: Wall, P.D. and Melzack, R., Eds., The Textbook of Pain (2nd Ed., pp. 220-230), Churchill Livingstone, London.

[20] Mindus, P. (1987) Pain and Sedation: Some Psychiatric Aspects. Acta Anaesthesiologica of Scandinavia, 32, S88, 7-12.

[21] Edell-Gustafson, U.M. and Hetta, J.E. (1999) Anxiety, Depression and Sleep in Male Patients Undergoing Coronary Artery Bypass Surgery. Scandinavian Journal of Caring Sciences, 13, 137-143.

[22] Kagan, I. and Bar-Tal, Y. (2008) The Effect of Preoperative Uncertainty and Anxiety on Short-Term Recovery after Elective Arthroplasty. Journal of Clinical Nursing, 17, 576-583. http://dx.doi.org/10.1111/j.1365-2702.2007.01968.x

[23] Mitchell, M. (2009) General Anaesthesia and Day-Case Patient Anxiety. Journal of Advanced Nursing, 66, $1059-1071$. 
http://dx.doi.org/10.1111/j.1365-2648.2010.05266.x

[24] Majasaari, H., Paavilainen, E. and Astedt-Kurki, P. (2007) The Visible and Invisible Family: Nurses’ Perceptions of Counselling in Day Surgical Nursing. Journal of Advanced Perioperative Care, 3, 11-19.

[25] Kiecolt-Glaser, J.K., Glaser, R., Gravenstein, S., Malarky, W.B. and Sheridan, J. (1996) Chronic Stress Alters the Immune Response to Influenza Virus Vaccine in Older Adults. Proceedings of the National Academy of Sciences of the United States of America, 93, 3043-3047. http://dx.doi.org/10.1073/pnas.93.7.3043

[26] Contrada, R.J., Leventhal, E.A. and Anderson, J.R. (1994) Psychological Preparation for Surgery: Marshaling Individual and Social Resources to Optimize Self-Regulation. In: Maes, S., Leventhal, H. and Johnson, M., Eds., International Review of Health Psychology, Wiley, New York, 219-266.

[27] Devine, D.E. (1992) Effects of Psychoeducational Care for Adultsurgical Patients: A Meta-Analysis of 191 Studies. Patient Education and Counseling, 19, 129-142. http://dx.doi.org/10.1016/0738-3991(92)90193-M

[28] Marucha, P.T., Kiecolt-Glaser, J.K. and Favagehi, M. (1998) Mucosal Wound Healing Is Impaired by Examination Stress. Psychosomatic Medicine, 60, 362-365.

[29] Padgette, D.A., Marucha, P.T. and Sheridan, J.F. (1998) Restraint Stress Slows Cutaneous Wound Healing in Mice. Brain, Behavior \& Immunity, 12, 64-73. http://dx.doi.org/10.1006/brbi.1997.0512

[30] Salomaki, T.E., Leppaleuoto, J., Laitinen, J.O., Vuolteenaho, O. and Nuutinen, L.S. (1993) Epidural Versus Intravenous Fentanyl for Reducing Hormonal, Metabolic, and Physiologic Responses after Thoractomy. Anesthesiology, 79, 672-679. http://dx.doi.org/10.1097/00000542-199310000-00007

[31] Kiecolt-Glaser, J.K., Page, G.G., Marucha, P.T., MacCullum, R.C. and Glaser, R. (1998) Psychological Influences on Surgical Recovery: Perspectives from Psychoneuroimmunology. American Psychologist, 53, 1209-1218. http://dx.doi.org/10.1037/0003-066X.53.11.1209

[32] Johnson, M. (1988) Impending Surgery. In: Fisher, S. and Reason, J., Eds., Handbook of Life Stress, Cognition and Health, Wiley, New York, 79-100.

[33] Pond, R.S., Brey, J. and DeWall, C.N. (2011) Denying the Need to Belong: How Social exclusion Impairs Human Functioning and How People Can Protect against It. In: Bevinn, S.J., Ed., Psychology of loneliness, Nova Science Publishers, New York, 107-122.

[34] Shaver, P. and Buhrmester, D. (1983) Loneliness, Sex Role Orientation and Group Life: Social Needs Perspective. In: Baulus, P.B., Ed., Basic Group Processes, Springer-Verlag, New York, 259-288.

[35] Olds, J. and Schwartz, R.S. (2009) The Lonely American: Drifting Apart in the Twenty-First Century. Beacon Press, Boston.

[36] Cacioppo, J.T. and Patrick, W. (2008) Loneliness: Human Nature and the Need for Social Connection. W.W. Norton, New York.

[37] Hawkley, L.C., Thisted, R.A., Masi, C.M. and Cacioppo, J.T. (2010) Loneliness Predicts Increased Blood Pressure: 5-Year Cross-Lagged Analyses in Middle-Aged and Older Adults. Psychology and Aging, 25, 132-141. http://dx.doi.org/10.1037/a0017805

[38] Heinrich, L.M. and Gullone, E. (2006) The Clinical Significance of Loneliness: A Literature Review. Clinical Psychology Review, 26, 695-718. http://dx.doi.org/10.1016/j.cpr.2006.04.002

[39] McWhirter, B.T. (1990) Loneliness: A Review of Current Literature with Implications for Counselling and Research. Journal of Counselling and Development, 68, 417-422. http://dx.doi.org/10.1002/j.1556-6676.1990.tb02521.x

[40] Booth, R., Bartlett, D. and Bohnsock, J. (1992) An Examination of the Relationship between Happiness, Loneliness, and Shy Men in College Students. Journal of College Student Development, 33, 157-162.

[41] Riggio, R.E., Watring, K.P. and Throckmorton, B. (1993) Social Skills, Social Support, and Psychosocial Adjustment. Personality and Individual Differences, 15, 275-280. http://dx.doi.org/10.1016/0191-8869(93)90217-Q

[42] Rokach, A. and Brock, H. (1997) Loneliness: A Multidimensional Experience. Psychology: A Journal of Human Behaviour, 34, 1-9.

[43] Dwyer, T.F. (2011) Family Caregiving across the Lifespan. Family Therapy Magazine, 10, 18-21.

[44] Novotney, A. (2009) Help for Caregivers. Monitor on Psychology, 41, 61-63.

[45] Rainer, J.P. and McMurry, P.E. (2002) Caregiving at the End of Life. Journal of Clinical Psychology, 58, $1421-1431$.

[46] Chentsova-Dutton, Y., Shucter, S., Hutchin, S., Strause, L., Burns, K., Dunn, L., Miller, M. and Zisook, S. (2002) Depression and Grief Reactions in Hospice Caregivers: From Pre-Death to 1 Year Afterwards. Journal of Affective Disorders, 69, 53-60. http://dx.doi.org/10.1016/S0165-0327(00)00368-2

[47] Pagnini, F., Rossi, G., Lunetta, C., Banfi, P., Castelnuovo, G., Corbo, M. and Molinari, E. (2010) Burden, Depression, and Anxiety in Caregivers of People with Amyotrophic Lateral Sclerosis. Psychology, Health \& Medicine, 15, 685-693. 
http://dx.doi.org/10.1080/13548506.2010.507773

[48] Chio, A., Gauthier, A., Calvo, A., Ghiglione, P. and Mutani, R. (2005) Caregiver Burden and Patients' Perception of Being a Burden in ALS. Neurology, 64, 1780-1782. http://dx.doi.org/10.1212/01.WNL.0000162034.06268.37

[49] Gauthier, A., Vignola, A., Calvo, A., Cavallo, E., Moglia, C. and Chio, A. (2007) A Longitudinal Study on Quality of Life and Depression in ALS Patient-Caregiver Couples. Neurology, 68, 923-926. http://dx.doi.org/10.1212/01.wnl.0000257093.53430.a8

[50] Goldstein, L.H., Atkins, L., Landau, S., Brown, R. and Leigh, P.N. (2006) Predictors of Psychological Distress in Carers of People with Amyotrophic Lateral Sclerosis: A Longitudinal Study. Psychological Medicine, 36, 865-875. http://dx.doi.org/10.1017/S0033291706007124

[51] O’connor, E.J., McCabe, M.P. and Firth, L. (2008) The Impact of Neurological Illness on Marital Relationships. Journal of Sex and Marital Therapy, 34, 115-132. http://dx.doi.org/10.1080/00926230701636189

[52] Chio, A., Gauthier, A., Montuschi, A., Calvo, A., Di Vito, N., Ghiglione, P. and Mutani, R. (2004) A Cross Sectional Study on Determinants of Quality of Life in ALS. Journal of Neurological Neurosurgery and Psychiatry, 75, 1597-1601. http://dx.doi.org/10.1136/jnnp.2003.033100

[53] Cobb, A.K. and Hamera, E. (1986) Illness Experience in a Chronic Disease-ALS. Social Science and Medicine, 23, 641-650. http://dx.doi.org/10.1016/0277-9536(86)90111-5

[54] Rokach, A. (1988) The Experience of Loneliness: A Tri-Level Model. The Journal of Psychology: Interdisciplinary and Applied, 122, 531-544. http://dx.doi.org/10.1080/00223980.1988.9915528

[55] Rowe, M.A. (1996) The Impact of Internal and External Resources on Functional Outcome in Chronic Illness. Research in Nursing \& Health, 19, 485-497. http://dx.doi.org/10.1002/(SICI)1098-240X(199612)19:6<485::AID-NUR4>3.0.CO;2-K

[56] Rattray, M., Johnston, J.A. and Wildsmith, W. (2005) Predictors of Emotional Outcomes of Intensive Care. Anesthesia, 60, 1085-1092. http://dx.doi.org/10.1111/j.1365-2044.2005.04336.x

[57] Mishel, M.H. (1997) Uncertainty in Acute Illness. Annual Review of Nursing Research, 15, 57-80.

[58] Raps, C.S., Peterson, C., Jonas, M. and Seligman, M.E.P. (1982) Patient Behavior in Hospitals: Helplessness, Reactance, or Both? Journal of Personality and Social Psychology, 42, 1036-1041. http://dx.doi.org/10.1037/0022-3514.42.6.1036

[59] Seeman, M. and Seeman, T.E. (1983) Health Behavior and Personal Autonomy: A Longitudinal Study of the Sense of Control in Illness. Journal of Health and Social Behavior, 24, 144-160. http://dx.doi.org/10.2307/2136641

[60] William, A.M., Dawson, S. and Kristjanson, L.J. (2008) Exploring the Relationship between Personal Control and the Hospital Environment. Journal of Clinical Nursing, 17, 1601-1609. http://dx.doi.org/10.1111/j.1365-2702.2007.02188.x

[61] Gardner, T.F., Nnadozie, M.U., Davis, B.A. and Kirk, S. (2005) Patient Anxiety and Patient Satisfaction in Hospital-Based and Freestanding Ambulatory Surgery Centers. Journal of Nursing Care Quality, 20, 238-243. http://dx.doi.org/10.1097/00001786-200507000-00008

[62] Rosen, S., Svensson, M. and Nilsson, U. (2008) Calm or Not Calm: The Question of Anxiety in the Perianesthesia Patient. Journal of Peri-Anesthesia Nursing, 23, 237-246. http://dx.doi.org/10.1016/j.jopan.2008.05.002

[63] Elkins, G., Rajab, M.S., Marcus, J. and Staniunas, R. (2004) Prevalence of Anxiety among Patients Undergoing Colorectal Surgery. Psychological Reports, 95, 657-658. http://dx.doi.org/10.2466/pr0.95.2.657-658

[64] Dunkel-Schetter, C. (1984) Social Support and Cancer: Findings Based on Patient Interviews and Their Implications. Journal of Social Issues, 40, 77-98. http://dx.doi.org/10.1111/j.1540-4560.1984.tb01108.x

[65] Revenson, T.A., Wollman, A. and Felton, B.J. (1983) Social Supports as Stress Buffers for Adult Cancer Patients. Psychosomatic Medicine, 45, 321-331.

[66] Bloom, J.R. and Spiegel, D. (1984) The Relationship of Two Dimensions of Social Support to the Psychological Well-Being and Social Functioning of Women with Advanced Breast Cancer. Social Science and Medicine, 19, 831-837. http://dx.doi.org/10.1016/0277-9536(84)90400-3

[67] De Haes, J.C.J.M. and Van Knipperberg, F.C.E. (1985) The Quality of Life of Cancer Patients: A Review of the Literature. Social Science and Medicine, 20, 809-817. http://dx.doi.org/10.1016/0277-9536(85)90335-1

[68] Phillips, D. (1996) Medical Professional Dominance and Client Dissatisfaction: A Study of Doctor-Patient Interaction and Reported Dissatisfaction with Medical Care among Female Patients at Four Hospitals in Trinidad and Tobago. Social Science \& Medicine, 42, 1419-1425. http://dx.doi.org/10.1016/0277-9536(95)00290-1

[69] Polimeni, A. and Moore, S. (2002) Insight into Women’s Experiences of Hospital Stays: Perceived Control, Powerlessness and Satisfaction. Behaviour Change, 19, 52-64. http://dx.doi.org/10.1375/bech.19.1.52

[70] Baker, C.F. (1984) Sensory Overload and Noise in the ICU: Sources of Environmental Stress. Critical Care Quarterly, 
6, 66-80.

[71] Rokach, A. and Parvini, M. (2011) Experience of Adults and Children in Hospitals. Early Child Development and Care, 181, 707-715. http://dx.doi.org/10.1080/03004430.2010.483115

[72] Singer, B.A. (1983) Psychosocial Trauma, Defense Strategies and Treatment Considerations in Cancer Patients and Their Families. The American Journal of Family Therapy, 11, 15-22. http://dx.doi.org/10.1080/01926188308250131

[73] Kawachi, I. and Berkman, L. (2001) Social Ties and Mental Health. Journal of Urban Health, 78, 458-467. http://dx.doi.org/10.1093/jurban/78.3.458

[74] Wittenberg-Lyles, E., Demiris, G., Oliver, D.P. and Burt, S. (2011) Reciprocal Suffering: Caregiver Concerns during Hospice Care. Journal of Pain and Symptom Management, 41, 383-393. http://dx.doi.org/10.1016/j.jpainsymman.2010.04.026

[75] Rokach, A., Findler, L., Chin, J., Lev, S. and Kollender, Y. (2013) Cancer Patients, Their Caregivers, and Coping with Loneliness. Psychology, Health \& Medicine, 18, 135-144. http://dx.doi.org/10.1080/13548506.2012.689839

[76] Rokach, A. and Brock, H. (1998) Coping with Loneliness. The Journal of Psychology: Interdisciplinary and Applied, 132, 107-127. http://dx.doi.org/10.1080/00223989809599269

[77] Rokach, A., Orzeck, T., Moya, M. and Exposito, F. (2001) Loneliness in North America and Spain. Social Behaviour and Personality: An International Journal, 29, 477-489. http://dx.doi.org/10.2224/sbp.2001.29.5.477

[78] Riches, G. (2002) The Loss of Children: Thinking the Unthinkable. In: Mason, C., Ed., .Journeys into Palliative Care: Roots and Reflection, Jessica Kingsley Publishers, London, 135-153.

[79] Croog, S.H., Baume, R.M. and Nalbandian, J. (1995) Pre-Surgery Psychological Characteristics, Pain Response, and Activities Impairment in Female Patients with Repeated Periodontal Surgery. Journal of Psychosomatic Research, 39, 39-51. http://dx.doi.org/10.1016/0022-3999(94)00089-N

[80] Korporaal, M., van Groenou, M.I.B. and van Tilburg, T.G. (2008) Effects of Own and Spousal Disability on Loneliness among Older Adults. Journal of Aging and Health, 20, 306-325. http://dx.doi.org/10.1177/0898264308315431 